\title{
Specialization as a Personality Trait and Tendency: Introducing an Instrument of Measuring the Specialization Degree. Part 1
}

\author{
Cristian Vrachas ${ }^{1,2}$, George Leontakianakos ${ }^{3}$ \\ ${ }^{1}$ Faculty of Psychology, University of Philosophical and Social Sciences, Athens, Greece \\ ${ }^{2}$ Faculty of Biology, University of Natural Sciences, Thessaloniki, Greece \\ ${ }^{3} 4$ th High School of Halandri, Athens, Greece \\ Email: crisvrach@yahoo.gr
}

Received 10 August 2015; accepted 4 December 2015; published 7 December 2015

Copyright (C) 2015 by authors and Scientific Research Publishing Inc.

This work is licensed under the Creative Commons Attribution International License (CC BY). http://creativecommons.org/licenses/by/4.0/

(c) () Open Access

\begin{abstract}
Specialization constitutes a phenomenon which has been extensively researched in the framework both of the economic science-and its various structural cognitive fields-and also of the science of Biology. However, equivalent systematic attempt in evaluating the possible correlations and consequences of specialization in reference to multiple psycho-cognitive aspects of the individual's personality is not observable from the point of view of psychological science. Objective of the current study is the introduction of a theoretical model of specialization as a dynamic variable, as a trend, and from that stand point to evaluate a person's specialization degree in relation to other parameters of its psycho-cognitive being. In order to test the validity of the conception of specialization as a measurable factor, the Specialization Questionnaire (S.Q.) is created and introduced. More specifically, the S.Q. is aiming, on the one hand, at quantifying the degree of professional specialization and, on the other hand, at investigating the possible correlation between professional specialization and the tendency to seek for, respectively, specialized stimuli in other aspects of life, such as the personal-free time and the interpersonal relations.
\end{abstract}

\section{Keywords}

Specialization Questionnaire, Specialization Trend, Dynamic Measure, Personality Aspects 


\section{Introduction}

\subsection{Definition and Aspects of Specialization}

Specialization constitutes a term used in many areas of human activity and at the same time includes a variety of etymology approaches which depend on the framework. The Cambridge Dictionary (2015) defines specialization as "a particular area of knowledge or the process of becoming an expert in a particular area". According to the Oxford Dictionary (2015), means to "concentrate on and become expert in a particular subject or skill", and alternatively to "confine oneself to providing a particular product or service". In biological terms, to specialize means to "adapt or set apart (an organ or part) to serve a special function or to suit a particular way of life".

Various definitions have been proposed by different sources for the description- or the distinction-of different facets or functions of the specialization phenomenon. Wolfang Mewes proposes the term horizontal specialization in comparison to the respective term vertical specialization. The first, according to Brian Bloch (1995) "entails offering a specific target group a (relatively) complete solution to their problem (s). The wider the selection is, the shallower the depth of production is”. The latter, “... entails producing a very narrow range of products”. Olive Stevenson (2005) - making an evaluative retrospection of the concept, use and purpose of the term generism-links into a disjunctive relation the terms generic social work-a condition where “... values, knowledge and skills can be applied to a range of situations"-and specialization. In international literature is also found the term static specialization (the focusing of a company to what it already knows well to do) as an antipode to the term dynamic specialization, which expresses "the commitment to eliminate resources and activities that no longer differentiate the firm and to concentrate on accelerating growth from the capabilities that truly distinguish the firm in the marketplace” (The only sustainable edge, p. 54). Besides, Duranton \& Puga (2005) make use of the terms sectoral specialization - for describing the production's focus on certain sectors-and functional specialization, which is contrasted to the first one, as it concentrates on the analysis of management and services. Additionally, Bacolod et al. (2009) mention the terms opportunity effect (the state in which the soft skills ${ }^{1}$ of the workers are becoming more useful in an environment where more opportunities for interaction among them are given) and specialization effect (where the strict distinction of competence/activity replaces the soft skills of the working stuff). In scientific literature, the term specialization by firm is also used in order to describe the variety of different services and goods that a certain company offers or produces (Kalra \& Li, 2008).

Systematic and wide use of the term is taking place especially in the frames of two main scientific fields; on the one hand that of Biology and on the other hand that of Finance. Specialization, both as a concept and as a procedure, constitutes main subject of research of Biology and it is approached, in specific, by two sides: 1) in relation to the degree and quality of the survival strategies, which an organism in a given environment selects, and 2) in reference to the specializing and specialized function in cellular, histological and organic level of a given living organism, animal, plant, fungus or bacteria (Bradshaw, 1989; Nurmi \& Parvinen, 2008; LimorWaisberg et al., 2011; Adite et al., 2013)².

As far as the wider area of social sciences concerns, the concept of specialization is being extensively analyzed by the scientific field of Economic Sciences, and especially by the sub-fields of Business Administration and of Micro and Macro-economics. Thus, on the one hand specialization constitutes a research subject in reference to the consequences (positive or negative ones) reflected upon the production sector, either from the reference point of the microeconomic scale of a given company, or of a broader production field or of a national economy scale (Kim \& Meng, 2015; Fritsch \& Slavtchev, 2009; Aiginger \& Rossi-Hansberg, 2006). On the other hand, specialization is being tested for its effectiveness as an employee-managing strategy in the framework of the research for the most result-giving policy for maximizing the benefits of a given target factor, be that a company, a certain production sector, a national economy or the global transaction network (Gavrel \& Lebon, 2009; Parro, 2015). As a consequence, there is an extensive literature regarding the aspects of specialization, which in certain occasions can be utilized by various scientific fields and which encapsulates different aspects of the specialization effect, in relation to both financial as well as productivity matters, by proposing respectively various models which embrace or deny specialization. Accordingly, researches that focus on the specializing division of labor inside the marriage (Leahey, 2006; Lee \& Ono, 2008); the impact of specialization on productivity ratio, as well as on the employees' burn-out effect (Hsieh \& Chao, 2004), but also in the effective-

\footnotetext{
${ }^{1}$ The non-typical qualifications, requirements that a person must or may have in relation to its working outputs and environment. Such qualifications could be the communication and general social skills, positive personality characteristics, etc.

${ }^{2}$ The bibliography is highly indicative, with scientific articles covering a vast area on that subject.
} 
ness is certain sport areas, such as the penalty kicking in soccer (Baumann et al., 2011) constitute typical examples of the multiple functional facets of specialization.

On the contrary, the conceptual aspects and the functional parameters of specialization have not been systematically and sufficiently put into test, regarding the scientific field of Psychology. Furthermore, there is a lack of a basic research data concerning the correlation among the cognitive or the working specialization and various personality or cognitive aspects, with some noticeable exceptions, such as the highlighting of the multi-dimensional- and not linear-relation between the domain knowledge (i.e. academic specialization) and the personal interests (Lawless \& Kulikowich, 2006); the evaluation and application of a variety of the "specialist" models in the personality field research (Little, 1972); the comparison between the concept of the fragmentation of Psychology itself-with every sector being subjected to a specialized direction-, and a wholistic view of its purpose and duty (Moghaddam, 1989); the implications from the specialization in the psychological test making (Anastasi, 1967); the problematic over the application of specialization within the realm of Psychology (Sales, 1985); the investigation of a critical matter such as creativity in the framework of educational system, and the search of a way that cognitive specialization could work on the benefit of the team creativity (Shin \& Zhou, 2007).

\subsection{Perception of Specialization}

In ancient Greece the matter of specialization has been subjected to a philosophical problematic. Aristotle in his

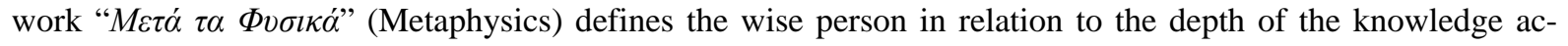
quired: "So, first of all, we consider the wise man to have knowledge of everything, to the possible extend, without having specialized knowledge for every single thing... These are our notions concerning the wisdom and the wise men. And among the wise people the one who mostly possesses the whole of science is by necessity the one who knows about everything, as he is the one who has knowledge, sort of way, of every partial thing. The knowledge about the general whole is something very difficult for the human, because it is very distant from the senses" (Collected Works of Aristotle, 1993). More extensive and characteristic is the systematization of specialization in the framework of the platonic model of the ideal State (Plato, 2006). The Greek philosopher introduces specialization as a state-social parameter, as it extends and covers the ensemble of the human activity (the professional status strictly coincides on the social and personal condition). More specifically, the ideal State

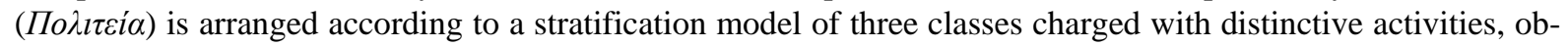
ligations and defining characteristics. On the top are the philosophers-lords, in the middle class are the guardians-protectors of the State (the best of who are acceded to the highest rank, which means the first class). The third and lower class is embodied by the merchandisers and in general by all those who are occupied with financial activities (whose obligation is to feed and preserve their class but also the rest of the classes).

Frederick W. Taylor is considered to be the first who systemized working specialization and introduced it as a managing method. To his own words: “...each workman has his own special abilities and limitations, and since we are not dealing with men in masses, but are trying to develop each individual man to his highest state of efficiency and prosperity” (Taylor, 1911). However, the promotion of a managing method that focuses on an absolute standardization and quantification of a person's work has been criticized (with the characteristic example of the Charlie Chaplin's critic on what he perceived as mechanization of man, in his movie Modern Times).

Professor Eleni Kalokairinou (2007), giving a philosophical interpretation of the modern bureaucratic-legal state, notes: "Moreover, in this kind of society the type of human that predominates is the skilful or the expert, the person, that is, who independently from anything else is a technocrat or mechanic. He is not interested, or, rather, he is not preoccupied to promote the common good of its society, since something like that violates the principle of neutrality which he accepts, but only the development of expertise in the specific field at which he is occupied. As a capable technocrat he is working to further improve his dexterity, while at the same time he lets the modern, liberal, bureaucratic state to define the boundaries in which the results of his science will be applied in society". Considering that very point of the social dimension of personal specialization, the biologist Byrke Zimmerman poses the question how can this unilateral professional-social self-definition offer more information regarding the activity and the intentions of the person: "Or to look at it another way, the external labels attached to categories of people (physicist, economist, historian, philosopher, psychologist, machinist, teacher, garbage collector, housewife, dancer, ball player) do not reveal whether they are engaged in a search to understand the truth behind some set of data or whether they have accepted a particular dogma and have closed their minds to further conceptual changes". 


\section{Main Discussion}

\subsection{Introducing Specialization as a Quantifiable Measure}

The current research is based upon the conception of specialization as a dynamic measure and more of a procedure rather than a static concept (whose content remains unchanged independently from the reference frame and its functional purposes). Understanding specialization as a procedure leads to the following consequence: every individual conceptualization of this term or any terminology used to describe a given expression or attribute of it, doesn't simultaneously entail a fragmentation of its content. Specialization constitutes a cohesive measure and what is tested in any given occasion is its influence on the different variables measured. One additional consequence of the dynamic state of specialization is that constitutes a measure that is open to fluctuation. Therefore, not only specialization can be submitted to measurement-extracting quantified data from a created for that purpose scale-, but also a given research can focus on finding a balanced point of optimal specialization degree, or otherwise of optimal specialized performance. For that reason the term specializing trend is introduced, in order to label the tendency of an individual to, consciously or by instinct, seek to raise its specialization status. That means, on the one hand, an attempt to deepen its relation to a certain cognitive/occupational field and, on the other hand, the diffusion of its specializing mentality into other areas of possible personal interest.

\subsection{Research Hypotheses}

The main goal of this study is to introduce an instrument that will adequately deliver quantifiable data concerning the specialization status of the person. By specialization status is defined the tendency of the person to either be involved or seek information or situations that demonstrate a given level of specialization. The tendency covers and includes more facets of the individual's personality and can be expressed in more levels of the overall human activity (personal time, social relations, working field). This goal is based upon the assumption that specialization does not constitute a static and unchanged condition with distinctive borderlines and limited fields of expression. Therefore, the purpose is not only to measure the cognitive and professional specialization status of the person, but also the tendency to seek further specialization in its working domain, as well as in other areas of its life, such as the social acquaintances and the personal interests and activities in its time.

The research is based upon the following hypotheses:

1) "The more specialized the academic profile and professional orientation of a person, the more it seeks to interconnect these fields with other areas of its life". That means that the higher the degree of working specialization, the higher the probability that the person will set the rest of its activities (such as its personal time) in line with the main one. In other words, the hypothesis suggests that the person who works in a specialized environment would also want to arrange the other aspects of its life in such a way that the incoming stimuli would demonstrate a degree of relation, of affinity. The relation between the above mentioned degrees is expected to be directly proportional. Therefore, the research goal of this partial question can be stated so: "It is under investigation the tendency of the person who acquires specialized working position to aim for specialization and in other aspects of its activity".

2) "The more specialized the academic profile and the working field of a person, the more it will seek to expand its specialization status". This hypothesis derives directly from the theoretical basis mentioned previously, according to which specialization is not a static value, rather than a dynamic one. So, the more a person it elevates the degree of specialization involved in its working activity, the more it will tend to optimize that level, in order to sustain its competitiveness. Therefore, the research goal of this partial question can be stated so: "It is under search the tendency of the person with increased specialization degree of cognitive-academic and/or working position to aim for specific stimuli and in other aspects of its activity".

3) "The more specialized the academic profile of a person, respectively, the more specialized is its professional orientation and vice versa". The above hypothesis is based upon the assumption that a person that has followed, systematically, studies aiming at a specific cognitive field it will concentrate on finding a job that will be lined up with its specialized academic background. Therefore, the research goal of this partial question can be stated so: "It is under research the correlation degree between cognitive-academic and professional specialization”.

\subsection{The Specialization Questionnaire (S.Q.)}

The questions set in the Specialization Questionnaire (S.Q.) are incorporated in three categories, which cover the 
total of the activities of the person: 1) the personal/free time, 2) the professional activity, and 3) the so$\mathrm{cial} /$ interpersonal relations.

The above 3 factors are divided in two levels: 1) activity level, 2) opinion level. The objective of that distinction is to search, on the one hand, a possible correlation degree between the actions and the intentions of the person for systemization of specialization in more levels of its personal and social life; and on the other hand the consistency between actions and opinions.

e.g.: Activity level: Your personal/social relations include individuals from your working/activity place?

$\square$ No $\square$ Probably no $\square$ Probably yes $\square$ Yes

Opinion level: Do you believe that the relation between individuals from the same occupational field contributes to their social advancement and progress?

$\square$ No $\square$ Probably no $\square$ Probably yes $\square$ Yes

The reason for having selected the 4 possible answers scale rather than the one with the standard 5 possible (in which the fifth choice lies in the middle among the negative and positive variations respectably) is depended on the attempt to decrease the "conformism noise". More specifically, the increasing accessibility of the average person to technological means and the capability to acquire information from various sources has made possible the knowledge of, at least, the basic principles and evaluations of Psychology regarding what it could be characterized as "average, non pathological behavior". That means that the individuals, because of the availability of the information provided regarding a variety of fields of Human Sciences, demonstrate the tendency to, as far as the public facet of their attitude it concerns, simulate or imitate those behavioral patterns that they view as widely acceptable by the society or they believe that will not give any reason for the expert to assume or diagnose elements of pathology (Castoriades \& Curtis, 1997; Papanoputsos, 2008).

Accordingly, the completion of a questionnaire which targets on the aspects and characteristics of the personality constitutes a field where the conformism noise increases, as the influential power of the need of the person to demonstrate the average, politically correct, behavioral patterns is present. In the case of the personality questionnaires, the conformism noise is reflected upon the trend of the subject to select the medium, "neutral" choice. This obstacle is traditionally coped methodologically with two ways: by using the appropriate statistical indicators which target in eliminating or at least decreasing this kind of noise, as well as with the randomization of the questions of the same thematic category inside the body of the questionnaire phrased in a different way in order to be ascertained whether the subjects gives answers that contradict each other or not. However, in the making of the current questionnaire was decided, apart from the two above mentioned approaches, to implement an additional means for diminishing that very conformism noise: the writing off of the possibility for one's choice of a medium, neutral and at the same time convenient, in every case, answer.

The Questionnaire is divided into two parts. The first part, titled Statistics, besides the necessary statistical information required (age, sex, education level, financial level), contains also a number of preliminary questions (3 in total) aiming at diagnosing the relation between the educational level and the type of profession of the subject, as well as the relation between its current professional or educational status and its original intentions/plans.

e.g.: The type of profession you are/were involved with is related to the content of your studies?

$\square$ Yes $\quad \square$ Relatively $\quad \square$ No

The second part consists of 32 questions of graduate deviation. Additionally, there is 1 question in which the subject is called to select among different definitions of the term specialization the one it thinks is the most representative:

e.g.: "Specialization is:

1) The perfection in a specific field, through the improvement of the data quality.

2) The effective function in a specific field, through the improvement of the data quality.

3) The limited in width but increased in depth function in a specific field, through accumulation of certain kind of data.

4) The one-dimensional function in a specific field, through focusing in a limited data background.

5) The concentrated function in a specific field, through focusing in a limited data width. "

This multiple-choice type question allows for a free evaluation of the subject's trend, and for a further crossexamination of its answer-content consistency. For that purpose, the definition in the middle (3) serves as a neutral point of reference, since it lacks attributes or explanatory elements that are either positively or negatively charged towards the concept of specialization. On the other hand, the two definitions ( 1 \& 2) that precede the 
middle one, evaluate specialization as a rather positive procedure, whereas the two which follow (4 \& 5) conceptualize specialization in a negative manner.

\section{Conclusion}

Even though specialization constitutes a procedure, whose consequences are related to a wide range of the person's activity, its different aspects, as well as its various functions are the object of an extensive research, mostly by scientists from the fields of Biology and Economics. A sufficient literature covers, on the one hand, the study on the specialization mechanisms of cellular, tissue and organic structures of the living organisms, as well as the strategies of specialized adaptation in given environment. On the other hand, the research focuses on the macro and micro economic models of optimization of basic economical indicators-such as productivity, competitiveness, exportation, performance of the working force or personnel—in correlation to the comparative evaluation of the advantages and disadvantages of specialization and generalization.

However, regarding the consequences of specialization — as a procedure and as a condition —in the psychological, cognitive and social status of the person there is only few scattered and not interconnected data. Two possible explanations for that absence of sufficient data could be: 1) either that the existence and consequences of specialization-cognitive and professional-is being regarded by the psychologists as a given fact, inevitably connected to the psycho-social substance of the person inside the frame of the modern, western type society and economy; 2) or that the influence of specialization in the forming of the individual's personality and cognitive substance is considered to be unquestionably positive, so that, eventually, any attempt to analyze and define the aspects and consequences of specialization does not constitute a scientific necessity.

In both cases, it is left outside the realm of the systematic effort to research and understand a phenomenon of great importance and consequences to the psycho-social entity of the individual.

\section{References}

Adite, A., Sonon, S. P., \& Gbedjissi, G. L. (2013). Feeding Ecology of the Mangrove Oyster, Crassostrea Gasar (Dautzenberg, 1891) in Traditional Farming at the Coastal Zone of Benin, West Africa. Natural Science, 5, 1238-1248. http://dx.doi.org/10.4236/ns.2013.512151

Aiginger, K., \& Rossi-Hansberg, E. (2006). Specialization and Concentration: A Note on Theory and Evidence. Empirica, 33, 255-266. http://dx.doi.org/10.1007/s10663-006-9023-y

Anastasi, A. (1967). Psychology, Psychologists, and Psychological Testing. American Psychologist, 22, 297-306. http://dx.doi.org/10.1037/h0024521

Bacolod, M., Bernardo, B. S., \& William, S. C. (2009). Urban Interactions: Soft Skills versus Specialization. Journal of Economic Geography, 9, 227-262.

Baumann, F., Friehe, T., \& Wedow, M. (2011). General Ability and Specialization: Evidence from Penalty Kicks in Soccer. Journal of Sports Economics, 12, 81-105. http://dx.doi.org/10.1177/1527002510371194

Bloch, B. (1995). Specialization and Its Critical Role in Business; Wolfang Mewes’ Energo-Cybernetic Strategy in Relevant Tot Most Organizations and Even Individuals. Management Decision, 33, 51-56. http://dx.doi.org/10.1108/00251749510087650

Bradshaw, L. J. (1989). Hemispheric Specialization and Psychological Function. New York: Chichester.

Cambridge Dictionaries Online (2015). http://dictionary.cambridge.org/dictionary/british/specialization\#translations

Castoriades, C., \& Curtis, D. A. (1997). World in Fragments: Writings on Politics, Society, Psychoanalysis, and the Imagination. Redwood City: Stanford University Press.

Collected Works of Aristotle (1993). Metaphysics 1-Books A'- $\Delta^{\prime}$. In M. Vasileios (Ed.), Introduction, Translation, Comments: Anastasia-Maria Karastathi, Cactus (pp. 982a 8-25). Athens (in Greek): Book A.

Duranton, G., \& Diego, P. (2005). From Sectoral to Functional Urban Specialization. Journal of Urban Economics, 57, 343370. http://dx.doi.org/10.1016/j.jue.2004.12.002

Fritsch, M., \& Slavtchev, V. (2009). How Does Industry Specialization Affect the Efficiency of Regional Innovation Systems? The Annals of Regional Science, 45, 87-108. http://dx.doi.org/10.1007/s00168-009-0292-9

Gavrel, F., \& Lebon, I. (2009). Endogenous Job Specialization. Economic Modelling, 26, 328-334. http://dx.doi.org/10.1016/j.econmod.2008.07.015

Hsieh, A.-T., \& Chao, H.-Y. (2004). A Reassessment of the Relationship between Job Specialization, Job Rotation and Job Burnout: Example of Taiwan's High Technology Industry. The International Journal of Human Resource Management, 
15, 1108-1123. http://dx.doi.org/10.1080/09585190410001677331

Kalokairinou, E. (2007). Addendum. In M. Kuczewski, \& R. Polansky (Eds.), Bioethics: Ancient Themes in Contemporary Issues (pp. 527-584). Translation in Greek by M. Katsimitsis, Edited in Greek by K. Eleni. Athens: Traaulos.

Kalra, A., \& Li, S. B. (2008). Signaling Quality through Specialization. Marketing Science, 27, 168-184. http://dx.doi.org/10.1287/mksc.1070.0300

Kim, T., \& Meng, D. (2015). Dynamic Changes of China’s Export Specialization. Modern Economy, 6, 633-641. http://dx.doi.org/10.4236/me.2015.65060

Lawless, K. A., \& Kulikowich, J. M. (2006). Domain Knowledge and Individual Interest: The Effects of Academic Level and Specialization in Statistics and Psychology. Contemporary Educational Psychology, 31, 30-43.

http://dx.doi.org/10.1016/j.cedpsych.2005.01.002

Leahey, E. (2006). Gender Differences in Productivity: Research Specialization as a Missing. Gender \& Society, 20, 754-780. http://dx.doi.org/10.1177/0891243206293030

Lee, S. K., \& Ono, H. (2008). Specialization and Happiness in Marriage: A US-Japan Comparison. Social Science Research, 37, 1216-1234. http://dx.doi.org/10.1016/j.ssresearch.2008.02.005

Limor-Waisberg, K., Carmi, A., Scherz, A., Pilpel, Y., \& Furman, I. (2011). Specialization versus Adaptation: Two Strategies Employed by Cyanophages to Enhance Their Translation Efficiencies. Nucleic Acids Research, 39, 6016-6028. http://dx.doi.org/10.1093/nar/gkr169

Little, B. R. (1972). Psychological Man as Scientist, Humanist and Specialist. Journal of Experimental Research in Personality, 6, 95-118.

Moghaddam, F. M. (1989). Specialization and Despecialization in Psychology: Divergent Processes in the Three Worlds. International Journal of Psychology, 24, 103-116. http://dx.doi.org/10.1080/00207594.1989.10600036

Nurmi, T., \& Parvinen, K. (2008). On the Evolution of Specialization with a Mechanistic Underpinning in Structured Metapopulations. Theoretical Population Biology, 73, 222-243. http://dx.doi.org/10.1016/j.tpb.2007.12.002

Oxford English Dictionary (2015). Last Checked 31 July 2015. http://www.oxforddictionaries.com/definition/english/specialize

Papanoputsos, E. (2008). The Law of Determination: And More Essays. Athens: Noese. (In Greek)

Parro, F. (2015). Private Incentives for Specialization in a Changing and Unpredictable Labor Market. Theoretical Economics Letters, 5, 163-168. http://dx.doi.org/10.4236/tel.2015.52020

Plato (2006). Politeia (Vol. 1-2). Introduction, Translation, Comments, Addendum: Mauropoulos G. Theodoros. Athens: Zitros. (In Greek)

Sales, B. (1985). Specialization: Past History and Future Alternatives. Clinical Psychologist, 38, 48-52.

Shin, S. J., \& Zhou, J. (2007). When Is Educational Specialization Heterogeneity Related to Creativity in Research and Development Teams? Transformational Leadership as a Moderator. Journal of Applied Psychology, 92, 1709-1721. http://dx.doi.org/10.1037/0021-9010.92.6.1709

Stevenson, O. (2005). Generism and Specialization: The Story since 1970. British Journal of Social Work, 35, 569-586. http://dx.doi.org/10.1093/bjsw/bch298

Taylor, F. W. (1911). The Principles of Scientific Management. New York, London: Harper \& Brothers. 